\title{
Film, Arts and Culture as Community Outreach Tools
}

\author{
By Victor S. O. Yu \\ Spring 2010 Issue of KINEMA

\section{FILM, ARTS AND CULTURE AS COMMUNITY OUTREACH TOOLS: PERSPECTIVES FROM SINGAPORE}

\section{Introduction}

Singapore's vision of nationhood involves a sense of shared destiny based on multiculturalism. It cultural and creative vibrancy can be seen in terms of economic, political and social conditions governing the production and distribution of expression. Much coordinated efforts among government, businesses, filmmakers and arts leaders have taken place to ensure the arts and culture industry is creating significant economic benefits to the country.

Every major city in the Asia Pacific region is in the race for talent, competitiveness and economic success. In many of these cities, film, arts and culture is playing a central role in economic development and community life. It is essential to integrate film, arts and culture into Singapore's economic development initiatives and increase the vibrancy of and financial resources for its film, arts and cultural sectors. Singapore has often been criticised as lacking real creativity due to the dominance of the government in shaping the arts scene in Singapore. Perhaps, it may be advisable for the government to take a less active role in determining what art forms should evolve in Singapore, and let the market forces shape the creative landscape in the country.

This study focuses on the Singapore's government using the film and arts both as an economic as well as a community outreach tool. It raises some of the problems faced by filmmakers, artists and arts organizations. In this paper, we suggest that there are a number of influences at work in Singapore's arts policy system. These influences include mandates from a higher level of government and directives from the executive branch.

\section{Review of Literature}

Cultural globalization is an important aspect of social globalization. Cultural globalization may be best understood as a twofold phenomenon: (1) the "transmission or diffusion across national borders of various forms of media and the arts"; and (2) "a complex and diverse phenomenon consisting of global cultures, originating from the many different nations and regions" (Crane 2002,1).

Globalization is transforming both the content and the systems through which national and local cultures are produced, reproduced, distributed, and preserved. Cultural policymakers have to struggle to meet new challenges, as global political trends (e.g. decentralization, democratization) and global economic trends (e.g. privatization) create a new environment and place new outcome demands on arts managers. Transnational contact reveals differences and can propel convergence and harmonization. Singapore continues to search for new models and "best practices" to adapt to local needs and conditions.

Culture reflects and serves both the community and the individual needs, because it at once assures us of who we are and inspires us with intimations of the goals we might reach. Singapore's cultural policy pursues the twin goals of democracy and excellence. It makes the arts and our intellectual and cultural life more accessible to all. It helps to create the conditions under which the finest expressions of our creativity can be reached and enjoyed by both Singaporeans and the world community. Goulding, Shankar and Elliot (2002) suggests that consumer experience is linked to a series of behaviours, which include narcissistic identity, the emergence of new communities, the need for escape, engagement and hedonism. The Singapore government, through the National Arts Council and the Media Development Authority, has created a better environment for filmmakers and artists to display their works or to promote systems that assist filmmakers and artists to reach their intended audiences. 
Singapore's public sector has become more "businesslike", embracing the language and practices of the private sector : formulating mission statements, launching quality initiatives, being more proactive and entrepreneurial, ensuring greater choice, and embracing an ethic of consumerism. The current enthusiasm for the privatization of public administration favours de-bureaucratization, that is dismantling rigid structures and hierarchies, promoting decentralization, and maximizing flexibility even to the point of creating chaos. The key to organizational success lies not in the refinement of organizational structures - the definition of roles, rules, procedures, hierarchies, divisions, and channels of communication - but in the strengthening of organizational culture, that is, the system of core values, symbols, and rituals around which organizations are believed to cohere.

Many film and arts management researcher recognize the major challenges filmmakers and arts managers face in managing creativity and creative people. Byrnes (2003) writes "in an arts organization keeping the creative spirit alive is a full-time job for a manager". Palmer (1998) concludes that "managing creative people and aesthetic products requires different management skills than those found in mainstream business."

Culture connects one individual with another and makes the development of the individual possible. Culture defines how people relate to nature and their physical environment, and through which we express our attitudes to and beliefs in other forms of life, both animal and plant. All forms of development, including human development are determined by cultural factors. It is impossible to talk about culture and development separately, since they are so intertwined together. Cultural freedom is the condition for individual freedom to flourish. It embraces the obligations that are embedded in the exercise of individual rights. Every citizen has a duty to the community in which alone the free and full development of his or her personality is possible. Putnam (2000) agues that communities where citizens are more involved in cultural and other civic organizations have higher levels of "social capital", which results in more effective levels of governance. This is because "social networks and the norms of reciprocity and trustworthiness" that develop when people are involved in cultural activities (such as choirs, art gallery visits or cultural performances).

\section{Perspectives from Singapore:}

Singapore's culture is in a constant state of flux, influencing and being influenced by other cultures. Its culture, therefore, reflects its history, mores, institutions and attitudes, its social movements, and the configurations of political power. It is dynamic and continually evolving.

Singapore has reaped much benefits from being a multicultural country. However, the government is also vigilant of the risks of cultural conflicts. The government cannot determine a people's culture; on the contrary, the government is partly determined by it. However, the government is consciously influencing the path of cultural development in Singapore.

Singapore's basic principles of fostering of respect for all cultures that themselves tolerate others has gained much envies from the international community. Respect goes beyond tolerance and implies a positive attitude to rejoicing in other peoples culture. Social peace is an essential element for human and economic development in Singapore.

Film, art, culture and creativity at the neighbourhood level often include cultural expressions of ethnic, racial and special interests groups that may not be adequately represented in mainstream cultural institutions. Community activities can take place in arts-specific venues such as theatres, galleries and museums or non-arts-specific places such as community centres, church halls, libraries, parks or clubs. At the neighbourhood level, film, arts, culture and creativity are frequently valued for aesthetic and technical qualities as well as its linkage to other community processes. For example, many community centres in Singapore offer arts, design or culinary courses. These courses offer a platform for the transmission of heritage from one generation to another and the interpretation of life in a new environment. Many activities at the neighbourhood level are made possible through the collective efforts of both arts-specific and on-arts-specific entities. A church-based youth dance group, for example, may rely on support not only from 
the church, but from other youth service voluntary welfare organizations, artists, and arts organizations, among other sources.

In Singapore, the list of potential contributions that participation in film, arts, culture and creativity at the neighbourhood level may have included:

- $\quad$ Supporting civic participation and social capital

- $\quad$ Catalyzing economic development

- $\quad$ Promoting the sense of ownership of place

- $\quad$ Preserving cultural heritage

- $\quad$ Bridging cultural / ethnic / racial boundaries

- Transmitting cultural values and history

- $\quad$ Creating group identity

The concept of branding is integral to the creative city model. City brands are intended to provide international recognition. Most branding exercise are consumption oriented, using culture, sports or entertainment to attract both local and foreign consumers (Hanningan 2003). Branding can also focus on cultural attributes, such as multiculturalism or on specific cultural icons. For example, Singapore vie for the honour of having the world's largest Ferris Wheel (Singapore Eye). Bjorkman (2002) argued that companies which produced feelings that try to give meaning not only on the level as a marketing concept, is growing. His research introduced the concept of aura in marketing, which relates to the feeling and experience of beauty, exclusiveness, uniqueness and authenticity that a product, service or brand creates.

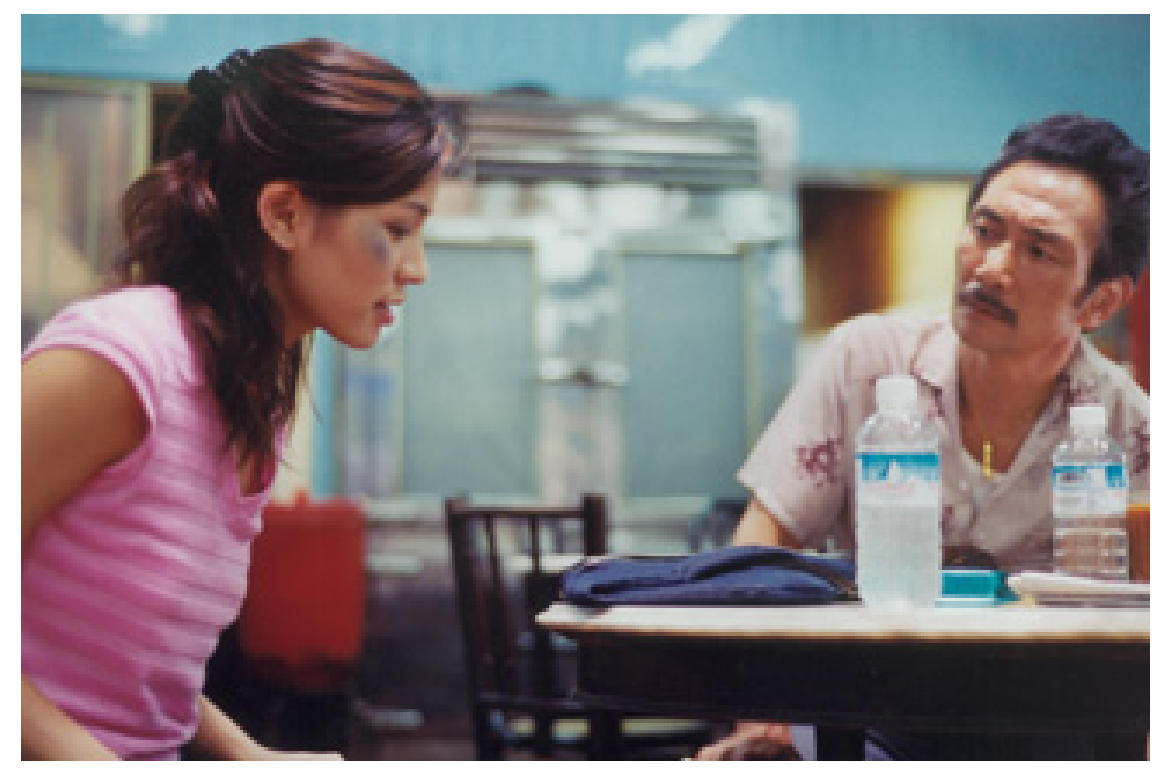

Figure 1: Perth by Djinn, 2004

Iconic cultural buildings such as museums or theatres make equally good city brands. The architectural brands, museums and other cultural amenities are intended to serve as focal points that attract tourist dollars and help promote a city's image as a dynamic cultural destination. The creative city approach seeks to attract highly skilled workers to the urban community. Florida (2002) stressed that a vibrant cultural scene is key to attracting the workers necessary to run the creative industries. According to Florida, what members of the "creative class" look for in communities are "abundant high quality amenities and experiences, an openness to diversity of all kinds, and above all else the opportunity to validate their identities as creative people". Florida claims that newly formed urban concentrations of creative people rest on the 3Ts of economic development: Technology, Talent and Tolerance. To attract creative people, a place must have all these three components. 
Singapore's creative city approach is both economically driven as well as arts-centred. Governance is at the central Ministry level, spearheaded by the Ministry of Information, Communication and the Arts. Funding comes from the Ministry level. This creative city approach focuses first on the macro-level, then the micro-level.

Singapore can learn from the experiences of New York City and New York State. It is widely known that arts are essential to the city of New York which is highly regarded for its cultural excellence and opportunity. Film and arts are also economic engines for New York City and New York State. The economic value of arts has increased by $86 \%$ in real terms in 2005 compared to 1983 and by $61 \%$ since 1993. In New York State, the non-profit arts sector provides cultural opportunities while also creating jobs and generating taxes. New York City also serves as the state's centre of arts-motivated tourism.

The concentration of film and arts activities into large cities enables firms to share a common pool of highly specialised inputs, the existence of which depends on there being a concentration of local buyers. The film, arts and culture industry in New York clearly displays economies of agglomeration. One industry is attracted to a given location because it can make use of input already drawn to that place by another industry. For example, Hollywood became the movie production centre because the presence of some firms attracted others which could use the same specialised input available there.

Strategic partnerships between education institutions and arts practitioners is important to develop and sustain the creative industries. Each partner should be conscious of differences in the values, goals, resources and roles. Letona (1999) notes that partnership success comes from open contractual relationships where collaborations benefits both consumers and communities, and where partnerships are established to solve problems such as inefficiency, diffuse public accountability and a lack of responsiveness. Understanding the different values and goals that partners bring is crucial to the success of the partnership.

Film, arts and cultural organizations may partner with organisations outside the non-profit arts and cultural arena. Such partners include the commercial arts organizations, non-government agencies, educational agencies and religious institutions. Such partnership may be in the form of funding relationships between arts organizations and the philanthropic organizations and corporations which support them.

Singapore has introduced a number of initiatives to attract international media companies. These include:

1) Position Singapore as an Asian media marketplace:

The Media Development Authority (MDA) seeks to position Singapore as an ideal marketplace for the creation, development and distribution of media content and services. It will create events incorporating media markets in partnership with international players. It has established the Media Awards to enhance the value and marketability of award-winning content and talent.

2) Develop Singapore as a Media Financing Hub:

MDA hopes to provide a platform for financiers to provide debt or equity financing to media companies and projects. It is also working closely with industry players to set up a media investment fund to finance a range of local media projects.

3) Enhance knowledge of intellectual property rights and digital rights management tools: MDA seeks to facilitate training and consultancy to help enhance industry knowledge regarding Intellectual Property Rights laws as well as the latest developments in digital rights management tools.

4) Establish content development scheme:

MDA has introduced schemes to boost the range and quality of local films and television for export. The projects could be in collaboration with foreign partners.

5) Increase bilateral co-production agreements:

MDA and other government agencies such as International Enterprises Singapore can help local companies 
form tie-ups with overseas government and industry organisations. This will pave the way for Singapore companies to enter into co-productions with foreign partners. They will also give them access to foreign financing and distribution networks.

With Singapore's highly efficient infrastructure and emphasis on cutting-edge technology, many in the international film and Television industry have chosen to have their work done in Singapore. Singapore is well-known for its skilled forces, IT infrastructure and strong intellectual property rights protection regime. This provides a multitude of opportunities for companies looking for creative and innovative media companies in Singapore.

\section{Singapore's Film and Television Industry}

The economic benefits that accompany film and television production are recognised internationally. This is evidenced in the mushrooming of film offices throughout the world, all of which are competing for both national and international film. In New York City, the economic impact of the commercial arts sector amounted to USD10 billion in 2005. Motion picture and television production is the arts industry largest component.

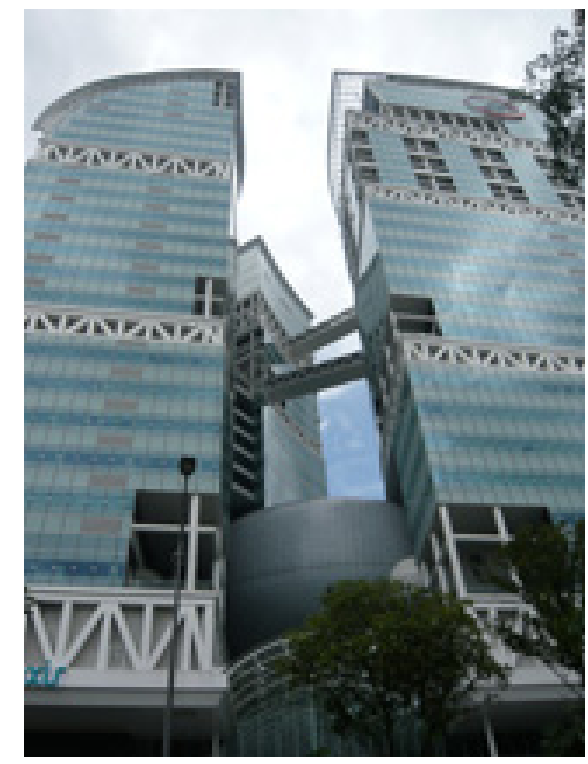

Figure 2: Fusionopolis - the new media centre

At present, Singapore is missing significant opportunities to grow an industry that creates many jobs and also spin-offs in the areas of exports and tourism. In the current climate of globalisation, it has become even more important for Singaporeans to feature their own stories. Films featuring local Singapore stories such as I Not Stupid, Money No Enough and 881 have made into the box offices in both Singapore and other Asian countries.

To maximise the significant opportunities for the film industry's growth in Singapore, investment in both ideas and infrastructures is vital. There are synergies between domestic and offshore production. A healthy film and television production sector provides complementary relationships with new media, education and screen.

The film, television and new media content creation industries have a major role to play in the knowledge economy. Singapore's traditional strengths in these industries position the country well to take up the opportunities of the future. Singapore's film and television industry is a collaborative, integrated

and cohesive industry. Through the support of the government agency, Media Development Authority, Singapore has attracted major film production companies internationally to come to Singapore. 
However, due to the small population of Singapore, there is a shortage of experienced writers, producers, directors, cast or crew. International studios are also vulnerable in the medium term to the ever rising cost of operations in Singapore.

\section{Film Festivals and Community Bonding}

Film festivals are important in Singapore to develop community bonding through:

Continuous visibility of audience interest for scheduled films

- $\quad$ A festival blog as a fast and easy way to communicate updates and promotions

- $\quad$ Audience feedback and analysis for planning future programs

- $\quad$ Provide temporary employment for local residents

- Generate local revenue

- $\quad$ Bolster local business

- $\quad$ Increase use of otherwise unused facilities

Film Festivals bring together a diverse array of powerful films, leading experts, and dynamic panelparticipants. Film festivals are powerful tools for community education, growth and enrichment. They provide a system in place for building networking alliances, which will provide long-term communication, referrals and a forum for cooperative community efforts into the future.

\section{Film and Arts Projects}

Film and arts projects in community settings differ from other projects because they incorporate practices of community strengthening. Filmmakers and artists and the community build networks and partnerships that enable projects to occur and build community capacity so that opportunities and links create life beyond the life of the projects.

Community arts projects have contributed enormously to the bonding of Singapore's community through a range of strategies, such as engaging disenfranchised members of the community, or producing valuable resources for a particular community. Within the community, increasing value is being placed on community activities which have positive impacts on the community. There is a growing recognition of the social and community well-being outcomes of community arts projects. The strongest and most sustainable projects not only foster links between the artists and community members, but create links with local organisations such as town councils, educational institutions and local non-governmental organisations. These broader partnerships generate the following benefits:

1. Provide additional resources and assistance to projects. The various agencies could come up with initiatives to support the involvement of the community in the planning and delivery of development and regeneration projects. They could work with artists at the project development stage and encourages local communities to take ownership of regeneration and renewal projects. An example is the rejuvenation of the Clarke Quay old warehouse site along the Singapore River into a vibrant area of economic activity.

2. Promote social inclusion and community cohesion by working with artists in regeneration projects. Public art can bond community together and lead to local empowerment.

3. Promotes capacity building in local communities through creating new opportunities. Involvement in public art projects can contribute to lifelong learning for individual participants through skills development and communication.

4. Support the change required to meet the community aspirations expressed in the artistic process (for example, creating a more supportive environment for people leaving prisons, an initiative of the government-sponsored Project Yellow Ribbon)

\section{Support to Smaller Organizations}

In the arts, entrepreneurial activity relates to activities which encourages imaginative and innovative thinking. It promotes confidence, initiative, informed risk-taking and perseverance. Arts entrepreneurs are those who create business opportunities. They are likely to fully utilize their social networks in audience development (Gummerson 1994) 
Irrespective of where they are located, small-to-medium sized arts organisation has limited access to government funding, which are often focused on larger projects. A lack of strategic support to these smaller arts organisations will have serious negative implications on the grassroots of the arts industry. The impact will also be felt upwards by larger arts sectors in that there will be fewer new works for production, fewer experienced artists and weaker links to audiences. A downturn in audiences, new works, and experienced arts professionals will have an adverse impact across the industry, affecting Singapore's reputation as a creative city.

The value of small arts organisations can be seen in the many benefits that they deliver. The Singapore government has to consider these issues in its policy making decisions:

1. Small arts organisations support cultural diversity by creatively engaging the communities from diverse backgrounds. They also provide a platform for creative engagement of diverse groups including multicultural communities and migrants.

2. Small arts organisations increase accessibility to the arts. They are able to engage diverse audiences including people who are underprivileged and with disabilities.

3. Small arts organisations support cultural export and tourism which include collaborations with other artists overseas.

4. Small arts organisations promote volunteering as they have limited access to government funding and have to rely largely on volunteers.

5. Small arts organisations create new and innovative works and are important to the artistic vitality and ongoing development of the arts in Singapore.

6. Small arts organisations also provide networking opportunities to foster knowledge sharing, professional development and help overcome isolation of the artists and arts organisations.

\section{Research Methodology}

The information for this study has been gathered in several ways: the most basic approach is simply to analyse the data collected by statistical agencies: audience participation, tickets sold, number of performing arts activities, etc. The research approach also includes exploring the literature on the subject, by conducting visits to arts institutions, and by conducting telephone, face-to-face interviews and survey questionnaires. The arts institutions are considered small in size and do not receive more than $\$ 0.5$ million of sponsorships from the government or private sector. These smaller institutions are chosen as they are more reflective of the arts and cultural scene in Singapore. These smaller players are important contributors to the vibrancy of the industry and employ a large proportion of arts professionals.

Telephone and face-to-face interviews and survey questionnaires were carried out with a total of 50 individuals, companies and local authorities who are involved in the arts. These included policy makers, artists and staff from arts companies who have a particular focus on delivering the arts to the communities. Surveyed arts organisation are involved in multiple art forms; dance (25\%), theatre (25\%), music (20\%), visual arts (20\%) and literary arts (10\%). The research interviews were designed and conducted in a manner that encouraged linguistic discourse and not in a way that sought a response (answer) to a specified stimulus (question). Questions asked were of an open nature and designed more to empower and enable respondents to tell their story rather than to elicit a specific response. Respondents were encouraged to elaborate on their responses. Additional questions were used to probe where clarifications or contextual understanding was required. These varied from one interview to another depending upon the respondent's story. The value which individuals attach to the arts will also affect their responses. This lack of standardization of the interviews was necessary to ensure the validity of the data to gain a thorough understanding of the knowledge and views of the respondents.

The site visits were designed to provide a qualitative understanding of how individual arts organizations approach the task of building arts participation. Topics that were discussed include how organizations defined its participation goals; how these goals related to its broader mission; how it designed and implemented its participation strategies; what techniques it used; how it interacted with its broader communities; how it defined and measured progress towards its goals; and what it viewed as major challenges to its participation-building programs. 


\section{Research Findings}

This paper examines the roles film, arts and culture play in community bonding. By promoting processes through which local residents take an interest in their own communities while building social links that bind neighbourhoods, film, arts and culture contribute to the social reconstruction that works in concert with economic revitalisation. The presence of arts organisations stimulates participation in the arts. There are a number of influences at work in Singapore's arts policy system. These influences include mandates from a higher level of government; directives from the executive branch; political influences exerted within elected political systems; and political influences exerted through lobbying from outside the elected political system. Policies are translated into actions through programs. The programs draw upon available resources such as cash, personnel, capital, information, in-kind contributions, and the like. They also focus on a particular set of societal behaviour they wish to affect. In the case of cultural industries, we would expect them to focus on one stage or another in the production process for cultural goods and services - training, creation, innovation, production, reproduction, etc. The intent of the arts policy is to affect behaviour in a way that would otherwise not be possible in the absence of that policy intervention. The intended outcomes would be increased participation, improved financial stability, increased competitiveness, higher levels of innovation, and the like.

The following findings were observed:

1. $\quad 73 \%$ of respondents strongly agreed that public schools should teach courses in arts and culture for credits

2. $\quad 55 \%$ of respondents agreed that it should also be taught after-school or as non-credit courses 3 . $\quad 61 \%$ of respondents strongly agreed that all students should be required to take arts, drama or music courses

4. $\quad 76 \%$ of respondents strongly agreed that government can do more to help individual artists develop

5. $\quad 71 \%$ of respondents strongly agreed that government should have the highest responsibility to support arts.

6. $\quad 73 \%$ of respondents strongly agreed that government should increase spending on specific arts programs

7. $58 \%$ of respondents agreed that immigrants bring diversity to Singapore's arts scene

8. $\quad 68 \%$ of respondents disagree that immigrants threaten Singapore culture

9. $68 \%$ of respondents felt that government does not consider public opinion seriously before implementing certain arts policies.

10. $73 \%$ of respondents strongly agreed that the current policy is focused disproportionately on funding the larger or elite arts and cultural organisations.

11. $75 \%$ of respondents strongly agreed that arts can play a key role in fostering community bonding

12. $68 \%$ of respondents agreed that members of the arts community can do more to advance public policy efforts

13. $53 \%$ of respondents agreed that private sector is supportive of the arts and culture in Singapore

14. $58 \%$ of respondents strongly agreed that Singapore has a successful arts culture as compared to other major cities

15. $62 \%$ of respondents agreed that Singapore has an appropriate support system for the arts

16. $70 \%$ of respondents agreed that arts activities successfully help to bring in visitors and tourists to Singapore

17. $68 \%$ of respondents agreed that family support is important to develop an interest in the arts

18. $52 \%$ of respondents believe that private interests can effectively invest their financial and intellectual capital to support public policy and community efforts.

19. $72 \%$ of the smaller arts institutions have poor earned revenues and poor fundraising results. This is partly attributed to their managers lacking marketing or fundraising skills.

The data collected showed that most respondents recognize the importance of arts in the education system. They also felt that the government should take the lead in supporting in the arts and more could be done to help the private sector. The consultation of public views could be improved further before policies are made. In general, the majority of respondents agreed that arts can play a key role in fostering 
community bonding. It would also be advisable for the government to be more involved in the process of trust-building and the incorporation of community needs in order to make the community sector more relevant. The key issue is that of directly contacting residents and, in so doing, promoting activities that were being designed.

A criticism of current public policy is that it is focused disproportionately on funding larger and more elite film, arts and cultural organisations. While regulation and investment in the more popular film, arts and cultural activities would form the central thrust of a cultural strategy, the government needs to identify other art forms that might form a foundation of funding strategy. The focus on an elite and small group may give rise to monopolies and oligopolies which may prevent new products and players from entering the markets. The risk is developing a restrictive institutional culture both in terms of management style and a narrow artistic expression. In spite of their distance from the government, they may fall prey to the need not to produce any works that may be seen as not favouring government policies, thus restricting their artistic expressions and creativity.

Singapore lacks the size and vibrancy of arts and culture sectors found in comparative cities like New York, Paris and Barcelona. There is considerable potential for film, arts and culture investments to be raised. A major constraint to the growth of Singapore's film, arts and cultural sector is the limited revenue base of its film, arts and cultural organisations. It is difficult for these organisations to build more vibrant and expanded programs and facilities while maintaining existing audiences without the resources necessary to accomplish this. Memberships, ticket sales and other sources are insufficient in themselves to cover the overhead costs.

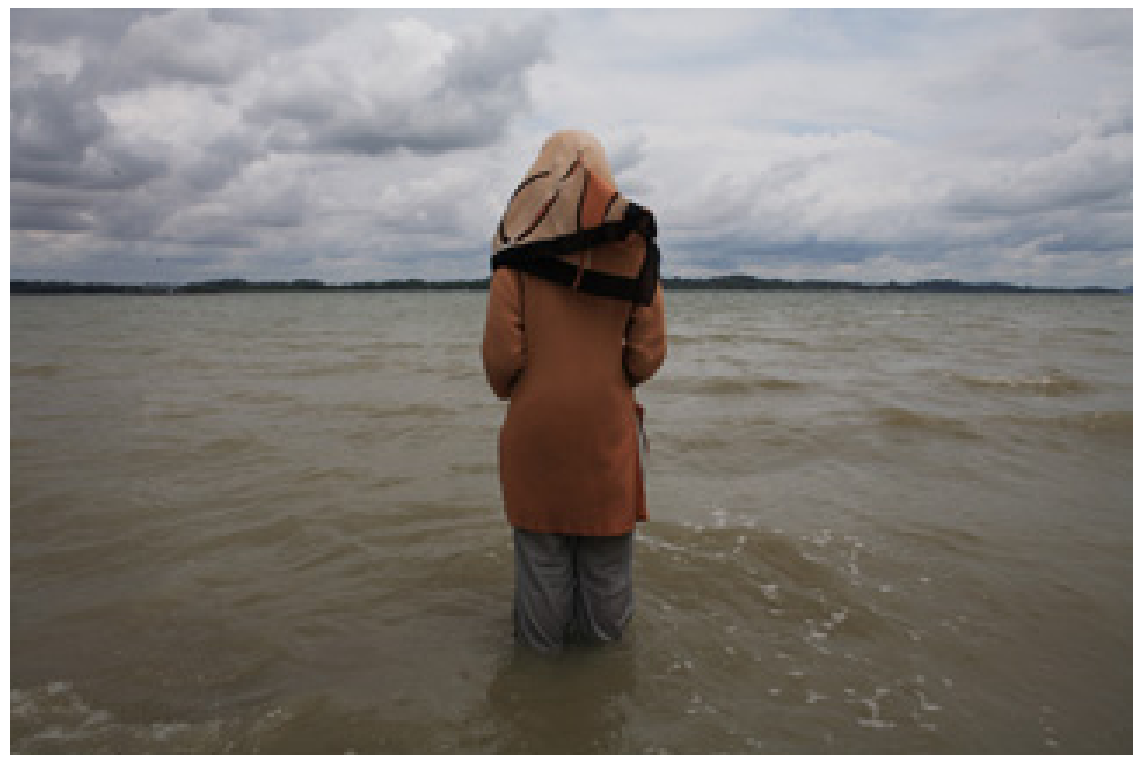

Figure 3: Lucky 7 by Sun Koh and other directors, 2008

Economic forces have prevented Singapore's cultural markets from functioning efficiently on their own to provide a variety of identifiably Singapore products and services to Singaporeans. The high unit costs of producing national products and services in the face of similar foreign content that are readily available makes survival of Singapore cultural content a major issue. Singapore firms need access to its own market to generate the necessary revenue for reinvestment in the creation, production and distribution of Singapore cultural products and services. To achieve this, policy makers need to introduce more initiatives which will help Singapore arts, cultural, media and design companies to increase their share of the domestic market, and to explore the use of more generous investment tax credits for production financing.

In a democracy, one looks for a correspondence between public opinions and the decisions of policy 
makers. In Singapore, however, the economic considerations are far more important. Many questions have been raised as to whether policy makers really care about what members of the public think. Are the policy makers always better able than the masses to judge what good policy is? Should policy be decided by those who are most involved with and have interest in an issue? Policy makers would reject the possibility that policy questions should be decided by people who lack proper background.

We also found that many Singapore citizens are willing to leave policy making to the experts. The involvement of an attentive public does not mean controversy, disagreement or agreement. Many policies have been decided by the policy makers first, after which the public is invited to provide feedback. The danger with Singapore's arts policy on the major issues of controversy is that policy makers and the majority of the public operate on very different assumptions and that the public feels that the policy makers cannot be trusted to act on their interests.

Singapore's arts policy has traditionally focused on the supply side. Arts institutions need to be supported, heritage sites need to be protected and certain arts forms need to be propped up. Funding and support have largely been targeted at large-scale organizations. We have not found convincing evidence that the public takes an active role in the shaping of arts and cultural policies. In a majoritarian vision of democracy, policy decisions should reflect the wishes of the majority. In a pluralist model, policy decisions reflect the competition among groups for benefits. Finally, in an elite politics model such as Singapore, policy decisions are left to a small group of individuals who generally share the same values and preferences. This last option is generally seen as applicable in the case of Singapore. Significant and sustained support is necessary to achieve the maximum impact on Singapore's economy, private and public funding support must be provided and sustained to accomplish this.

\section{Conclusion}

A creative society is open-minded, compassionate and lively. It respects and tolerates differences. It is able to meet challenges and adapt to changing situations, creativity, engagement, cohesiveness, well-being and respect for differences. Singapore has often been criticised as lacking real creativity due to the dominance of the government in shaping the arts scene in Singapore. Perhaps, it may be advisable for the government to take a less active role in determining what art forms should evolve in Singapore, and let the market forces shape the creative landscape in the country.

Creative city thinking yields an opportunity to take the lead in convening policy makers to discuss linkages among cultural, economic development and other community building initiatives. This is also an opportunity to involve grass-roots and community leaders to think "out-of-the-box" and build their stake and impact in the community.

Singapore's vision for film, arts and culture is to become a centre of creativity renowned for the diversity of arts and cultural experiences that contributes to the economic development of the nation. To achieve this vision, Singapore should:

1. Encourage the creation, import and export of a broad range of film, arts and cultural experiences.

2. Foster participation in film, arts and cultural activities that inform, educate and excite a broad range of audiences (both visitors and the local community)

3. Use economic incentives to support private, non-profit and for-profit organisations to integrate efforts and increase cooperation in the area of film, arts and culture.

4. Ensure that film, arts and culture thrive at the grassroots and community levels - in neighbourhoods and schools

5. Offer cultural experiences that relate to the country's history, environment and residents

6. Achieve a well-rounded system of support of funding for film, arts and culture through public, private and philanthropic organisations.

The government could up its support for projects which build on unique and diverse community attributes and promotes community bonding, such as:

- $\quad$ Artists-in-residence in the community 
- $\quad$ Projects which document community history and culture

- $\quad$ Showcases of local crafts, folk, traditional and ethnic arts

- $\quad$ Arts and civic dialogue projects

Filmmakers and artists make up the bedrock of the creative infrastructure. Singapore's concern with strengthening the non-profit arts community have focused on establishing stable larger film and arts organisations, promoting arts education, access and national participation in non-profit arts. This has probably been done at the expense of individual filmmakers and artists.

Singaporean artists are also relatively footloose; that is, they are not principally local-serving, and they are attracted to and held in some cities more than others. Singapore can amplify its artistic dividends, that is to say increase its artistic character by working on three fronts:

First, diversifying away from strictly "bricks and mortar" subsidies to arts facilities. Singapore can nurture artistic occupations in several ways. One is through the support for artists' "centres" - places where artists can come together to share their craft and to exchange business skills ideas. These centres also act as hothouses for developing artistic talents. The Government could also look into developing more residence-and-work spaces for artists. Greater concentrations of artists and arts-related organisations lead to higher degrees of arts participation among residents, directly and as audience members (Stern and Seifert, 2000).

Community-based organisations such as social services or self-help organisations, churches and community clubs are important sources of exposure to the arts for many artists early in their lives. They are important, ongoing sources of craft training for some ethnic-specific and immigrant artists.

To support the growing numbers of newly established film, arts and cultural organisations, the Singapore government could consider setting up a "venture" fund to encourage the creation of more significant activities. Resourceful people make today's economy work. It is important to develop, attract and retain highly creative individuals to work in film, arts, culture, design and other areas.

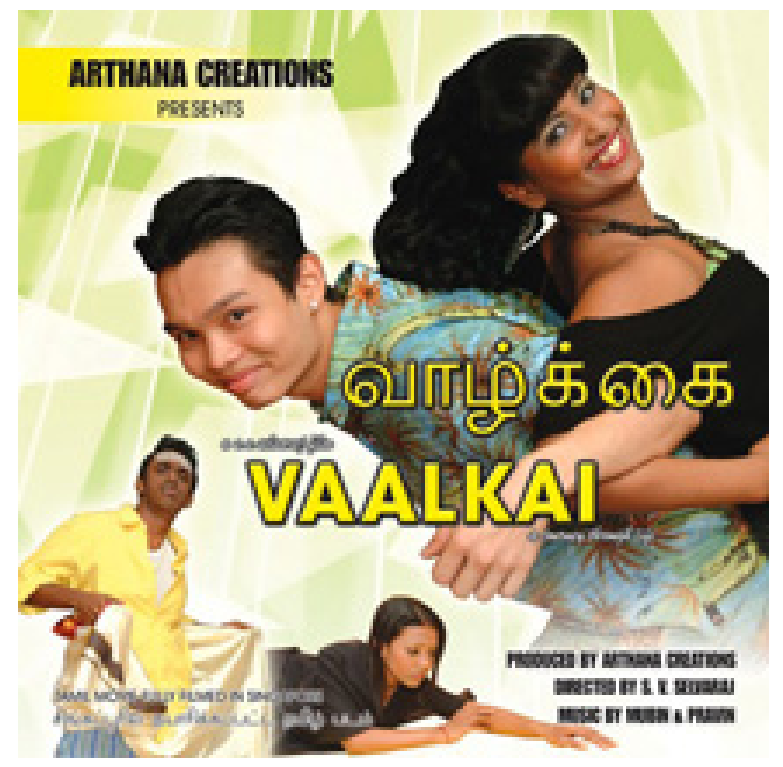

Figure 4: Vaalkai, a Tamil language film by S. V. Selvaraj

Develop close networks between the nonprofit and commercial arts. The authorities such as the National Arts Council and the Media Development Authority could sponsor smaller and more regular forums to connect filmmakers and artists of different disciplines and with other sectors such as web and product 
design, media, advertising, etc. This forum will create bridges between formal and informal arts, large institutions and smaller organizations.

Second, Singapore government can develop initiatives that strengthen the connections between corporations and resident artists and filmmakers. Traditionally, this relationship has been conceived as philanthropic in nature and has played an important role in supporting artists. But, artists can be viewed as talent available to help companies design a better product, write better manuals for workers or prepare better marketing materials. Agencies such as the Community Development Councils and grass-roots organisations can organise matchmaking sessions to match artists and corporations. This will contribute to a firm's productivity as well as artists livelihoods.

Third, the National Arts Council and the Media Development Authority could improve its decision criteria for allocating public dollars to film and the arts. Currently, large arts facilities and institutions tend to receive disproportionate shares of public dollar, because they are supported by well-organized organisations who lobby effectively. This is evidenced in the three government-backed arts academies, Nanyang Academy of Fine Arts, LASALLE College of the Arts, and the School of Arts. Smaller, more diverse private arts institutions receives no funding and support at all, though they are breeding grounds for future artists and make important contributions to the diverse character of the nation. A broader appreciation for the size and dimensions of artistic dividends will lead to a more holistic approach to arts funding and other support. While Singapore is supporting the development of the next and future generation of scholars through the provision of scholarships, fellowships, and doctoral research grants, the beneficiaries are limited only to students studying in the government tertiary institutions. The government has largely ignored students studying in private institutions, which are playing increasingly important roles in their contribution to Singapore as a global education hub. Policies should also be introduced to encourage broader, more regular and more timely exchange of research among the various segments of the cultural community. These exchanges of information and ideas are essential to the creation of knowledge in any field.

Smaller film and arts organisations and arts institutions play an important role in supporting the film, arts and cultural scene in Singapore through the following:

- $\quad$ They support cultural diversity by creatively engaging diverse groups and communities including youth and people with disabilities.

- $\quad$ They are also able to offer increase accessibility to the arts as they charge much lower prices for tickets to performances than the larger organisations.

- In addition, these smaller organisations promote volunteering as they rely heavily on volunteers and unpaid staff. Many of these smaller organisations rely heavily on social networking to attract volunteers.

- $\quad$ They also provide a platform for creative engagement of diverse groups in the community to come together.

Leadership training is essential to nurture arts leaders of tomorrow. Bringing filmmakers, artists, arts educators, arts organisations and teachers together for leadership training is important in order for everyone to understand their commonalities and to have a shared vision.

Marketing managers in the arts industry must take a leadership role in the development of branding and positioning of the arts organisations. An important element of leadership in arts marketing is the building of a diversified market. Film and arts organisations should put in more efforts to build a positive image and establish a sense of ownership among members of the community. A film and arts organisation has to develop a vision of where it stands in the minds of potential consumers, and what benefits these consumers hope to gain. Filmmakers and artists must also take responsibility for connecting with and educating the public about their work.

Policy makers have to understand the roles that more established artists can play in assisting younger artists. They can act as mentors helping young aspiring filmmakers and artists master professional ethics and navigate the risks of breaking into the art world. They can also act as facilitators ensuring that young 
people have access to the skills and expressions needed to be full participants in this new era.

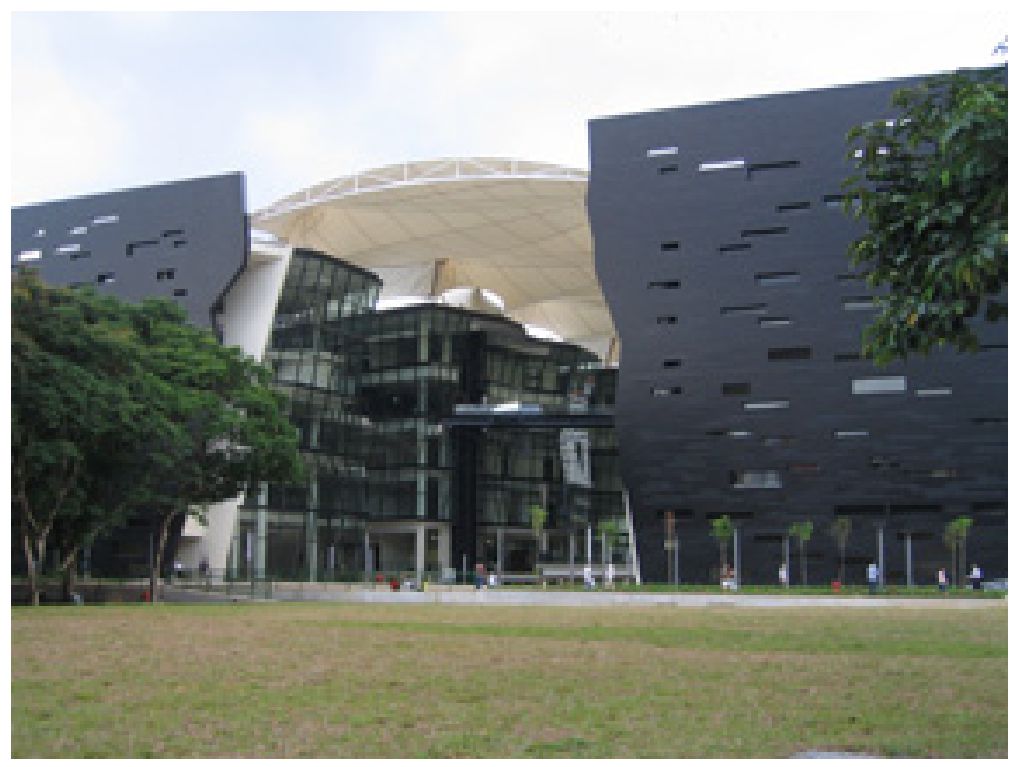

Figure 5: LASALLE College of the Arts, Singapore

\section{References}

Bjorkman, I. 2002. "Aura: Aesthetic Business Creativity". Consumption, Markets 8 Culture, 5(1): 69 - 78. Byrnes, W. J. 2003 Management and the arts. Focal Press.

Crane, D. (2002) Culture and globalization: Theoretical models and emerging trends. In Global Culture: Media arts, policy, and globalization, ed. D. Crane, N. Kawashima, and K. Kawasaki, 1-25. New York: Routledge.

Florida, Richard (2002), The Rise of the Creative Class, New York: Basic Books.

Goulding. C, Shankar. A, and Elliot, R. 2002, "Working Weeks, Rave Weekends: Identity Fragmentation and the Emergence of New Communities", Consumption, Markets \& Culture, 5(4): 261- 84.

Gummerson, E. 1994, "Making relationship marketing operational", International Journal of Service Management, $5(5): 5-20$.

Hanningan, J. 2003. Symposium on branding, the entertainment economy, and urban place building: Introduction. International Journal of Urban and Regional Research 27 (2): 352 - 60.

Letona, M. (1999). The government B nonprofit relationship: Towards a partnership model. Washington, DC: Nonprofit Sector Research Fund.

Markusen, A. \& King. D. (2003). The artistic dividend: The arts hidden contributions to regional development. Minneapolis: University of Minnesota, Humphrey Institute of Public affairs. Project on Regional and Industrial Economics.

Palmer, I. 1998 Arts managers and managerialism: A cross-sector analysis of CEO orientations and skills. Public Productivity and Management Review 21 (4): 433-52.

Putnam, R. D. 2000. Bowling Alone: The collapse and revival of American community. New York: Simon and Schuster. 
Stern, Mark J, and Seifert, Susan C. 2000. "Cultural Participation and Communities: The Role of Individual and Neighbourhood Effects." Philadelphia: University of Pennsylvania School of Social Work.

\section{Author Information}

Victor S. O. YU is Professor of Management at Dutch Delta University, Netherlands. His research interests include Strategic Management and Organizational Behaviour. He is also the Principal of the Cavalry School of Management and Design in Singapore. 